\title{
Comparison of Spider Web and Moss Bag Biomonitoring to Detect Sources of Airborne Trace Elements
}

\author{
Neele van Laaten $(\mathbb{D} \cdot$ Dirk Merten $(\mathbb{D})$ - Wolf von Tümpling • \\ Thorsten Schäfer • Michael Pirrung
}

Received: 24 April 2020 / Accepted: 22 September 2020 / Published online: 30 September 2020

(C) The Author(s) 2020

\begin{abstract}
Atmospheric particulate matter has become a major issue in urban areas from both a health and an environmental perspective. In this context, biomonitoring methods are a potential complement to classical monitoring methods like impactor samplers, being spatially limited due to higher costs. Monitoring using spider webs is compared with the more common moss bag technique in this study, focusing on mass fractions and ratios of elements and the applicability for source identification. Spider webs and moss bags with Hypnum cupressiforme were sampled at the same 15 locations with different types of traffic in the city of Jena, Germany. In the samples, mass fractions of 35 elements, mainly trace metals, were determined using inductively coupled plasma-optical emission spectroscopy (ICP$\mathrm{OES}$ ) and inductively coupled plasma-mass spectrometry (ICP-MS) after aqua regia digestion. Significantly
\end{abstract}

Electronic supplementary material The online version of this article (https://doi.org/10.1007/s11270-020-04881-8) contains supplementary material, which is available to authorized users.

N. van Laaten $\cdot$ D. Merten $\cdot$ T. Schäfer $\cdot$ M. Pirrung Institute of Geosciences, Applied Geology, Friedrich Schiller University Jena, Burgweg 11, 07749 Jena, Germany

N. van Laaten $(\bowtie)$

International Max Planck Research School for Global

Biogeochemical Cycles, Max Planck Institute for

Biogeochemistry, Hans-Knöll-Straße 10, 07745 Jena, Germany

e-mail: neele.van-laaten@uni-jena.de

W. von Tümpling

Helmholtz Centre for Environmental Research - UFZ,

Brückstraße 3a, 39114 Magdeburg, Germany higher mass fractions in spider webs than in moss bags were found, even after a much shorter exposure period, and could not be ascribed completely to a diluting effect by the biological material in the samples. Different mechanisms of particle retention by the two materials are therefore assumed. More significant correlations between elements have been found for the spider web dataset. Those patterns allow for an identification of different sources of particulate matter (e.g. geogenic dust, brake wear), while correlations between elements in the moss bags show a rather general anthropogenic influence. Therefore, it is recommended to use spider webs for the short-term detection of local sources while moss bag biomonitoring is a good tool to show a broader, long-term anthropogenic influence.

Keywords Biomonitoring - Spider webs · Moss bags · Urban particulate matter $\cdot$ Heavy metals

\section{Introduction}

Particulate matter (PM) in the atmosphere is regarded as one of the major environmental and health issues worldwide. This is of special importance in urban areas where people are exposed to enhanced levels of PM (Furusjö et al. 2007; Landrigan et al. 2018). The exposure to dust particles leads to health issues as premature mortality with up to 3.15 million estimated deaths per year worldwide, (lung) cancer, and a variety of respiratory and cardiovascular diseases (Lelieveld et al. 2015; WHO 2013). Furthermore, the atmospheric transport of 
particles influences the atmosphere itself and element cycling in the environment: PM scatters and absorbs radiation, and particles can act as cloud condensation nuclei (Gieré and Querol 2010). Enhanced levels of PM thus influence both weather and, on a longer time scale, climate. With deposition, particles can introduce metals into ecosystems. Known examples are the deposition of metals onto soils or into forest ecosystems (Fang et al. 2005).

Threshold values for atmospheric PM and metals attached to it have thus been set (e.g. European Union 2004, 2004/107/EC; European Union 2008, 2008/50/ EC) and monitoring stations have been installed in many urban areas. Due to the high costs and need for space, most of the cities only hold one or a few stations (Kardel et al. 2011). As levels and composition of PM can change rapidly within hundreds or even tens of meters, those stations have only a poor spatial coverage (Salmond and McKendry 2009). Simple and costeffective complementary tools are the biomonitoring techniques (Ștefănuţ et al. 2019): Airborne pollutants are adsorbed by a variety of biological materials that are sampled in the area of interest and analyzed. Typical matrices include not only mosses, lichen, and plant leaves but also tree bark and needles (Norouzi et al. 2015; Tretiach et al. 2011; Urbat et al. 2004). The advantage of biomonitoring methods is their lack of need for both power supply and maintenance, leading to low sampling costs. Furthermore, plants are widely distributed; hence, a large number of sampling sites are accessible (Berisha et al. 2017; Vuković et al. 2016).

An advanced technique is the moss bag biomonitoring. There has been a growing scientific interest in this technique within the last decades, as it is more controllable than classical moss monitoring and can be applied at every desired location (Ares et al. 2012). Moss of selected species from a remote place is put into bags of plastic mesh and exposed to ambient air at the locations of interest (Aničić Urošević and Milićević 2020). Afterwards, the mass fractions of selected elements or chemical compounds in the individual samples are determined (Capozzi et al. 2020; Di Palma et al. 2017; Shvetsova et al. 2019).

Another relevant biomonitoring technique is the collection of spider webs, to whose adhesive silk dust particles can attach. Spiders are widespread, wellknown arthropods that can survive adverse environmental conditions like heavy metal pollution due to strong physiological responses including the production of detoxifying enzymes (Ayedun et al. 2013; Babczyńska et al. 2006). Their webs can be found at many locations in urban areas and can be collected easily, for example, from fences, handrails, and walls (Rybak et al. 2012; Xiao-li et al. 2006). Despite the fact that this is a noninvasive method (if webs are not collected too often, e.g. every 2 weeks), this method has only been studied a few times so far (e.g. Górka et al. 2018; Rybak 2015; Xiao-li et al. 2006). However, the results point out that it is a promising technique for monitoring of PM. More recent studies have also focused on indoor air pollution, using webs of naturally occurring as well as laboratory-bred spiders (Rutkowski et al. 2019; Rybak et al. 2019).

To the best of our knowledge, no systematic comparison between the sampling of spider webs and moss bag biomonitoring has been done so far. Both methods have been applied individually, showing their suitability to assess levels of atmospheric pollution. However, the question arises if both methods lead to the same conclusions. This would mean that one method can replace the other or sampling campaigns can be combined, exploiting the advantages of both methods. Mass fractions of numerous trace elements (mainly heavy metals) in the spider web and moss bag samples from the same locations shall be determined and compared in this work. The questions we address in this paper are as follows: (a) Do the two biological materials show the same retention of dust particles? (b) Do the individual datasets contain patterns that can be used to identify sources of PM? And (c) Are the patterns and the resulting grouping of samples similar for both biomonitoring methods?

\section{Materials and Methods}

\subsection{Monitoring Sites}

For sampling, 15 locations in the city of Jena were chosen (Fig. 1). Jena is a medium-sized city in Central Germany without big industries; therefore the local air quality is expected to be mainly influenced by traffic on two railroad lines, two federal highways and a motorway. As the city is located in a valley formed by the river Saale, the sampling locations cover its north-south orientation and include locations with car traffic (prefix $\mathrm{CA})$, tram and train transport (TR) as well as areas reserved only for pedestrians (PD). 

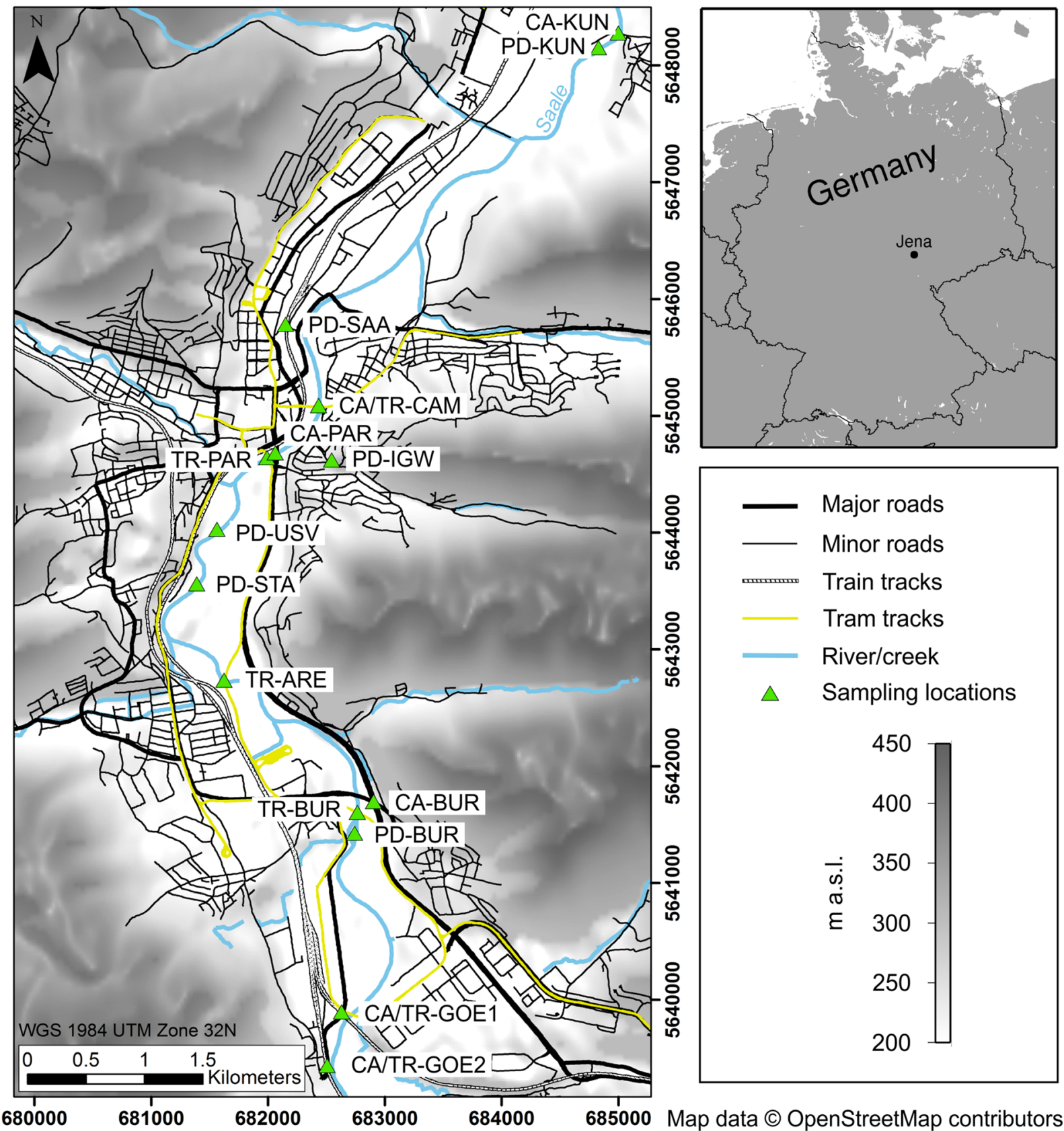

Fig. 1 Map of the city of Jena including traffic routes and the sampling locations coded according to the nearby type of traffic. $\mathrm{CA}$, car traffic; $\mathrm{CA} / \mathrm{TR}$, car and tram/train traffic; $\mathrm{PD}$, pedestrian

areas; TR, tram/train traffic. The map has been created using SRTM3 topography data (USGS 2004) and GMT (Wessel et al. 2013)

\subsection{Moss Bag and Spider Web Biomonitoring}

The preparation of moss bags was performed combining the approach of Adamo et al. (2008) with recommendations for more uniform exposure given by Ares et al. (2012). Hypnum cupressiforme was collected in a pine forest about $15 \mathrm{~km}$ south of Jena (UTM $32 \mathrm{~N} \mathrm{E}$ 687024 N 5631097). Foreign objects like pine needles and soil fragments as well as dead moss material were removed manually before the moss was rinsed three times with deionized water and dried at $40{ }^{\circ} \mathrm{C}$. The bags were made of polyester mesh $(16 \times 16 \mathrm{~cm}, 2-\mathrm{mm}$ mesh 
size) sewed with nylon thread and rinsed with diluted $\mathrm{HNO}_{3}$ (Merck, subboiled) and ultrapure water (genPure UV-TOC, Thermo Scientific) before use. A flat design has been chosen as it is expected to be most comparable with two-dimensional spider webs. Three grams of the dry moss was filled into each bag and the bags were stored in a polyethylene (PE) pouch until exposure. The bags were hung up at lamp posts $2.5 \mathrm{~m}$ above ground level, one of the heights that yielded the most replicable results in Ares et al. (2014). Plastic mountings that kept the moss away from the metal lamp poles were used for this purpose. After 10 weeks (from June to August 2017), the bags were removed. In the middle of this exposure period, webs of orb-weaving spiders (Araneidae) were sampled at the same locations. Additional samples were taken every 2 weeks at locations TR-ARE and CA-BUR to check for temporal variability. Spider webs were collected from the upper half of handrails $(0.5-1.2 \mathrm{~m}$ above ground level) by coiling the webs up on the upper half of a plastic straw (polypropylene, PP). Since the handrails were rather narrow (maximum $10 \mathrm{~cm}$ ), they do not effectively shield the webs from vertical dust deposition. Webs from the lower half of handrails were not sampled as they are expected to be influenced by wear of the underlying road surface. All intact webs available at one site made up one sample containing tens up to two hundred of intertwined individual webs. Since orb-weaving spiders renew their web almost every day (Nentwig 1980), the sampled webs reflect mainly PM from the day of the sampling, not exceeding a period of 6 days since the latest rainfall (that would have destroyed all older webs). Lamp posts for moss bag exposure were either directly above the handrails or maximum $10 \mathrm{~m}$ away but with the same distance to the next road or tram tracks. All samples were stored in individual PE bags during transportation to the lab.

\subsection{Sample Preparation and Analysis}

Mosses were removed from the bags and dried at $40{ }^{\circ} \mathrm{C}$. Each sample was cryo-milled using liquid nitrogen and a ceramic mortar and pestle. The spider webs were first removed from the plastic straws. Coarse objects like insects or hairs were sorted out manually using plastic tweezers before drying at $40{ }^{\circ} \mathrm{C}$. All samples were digested with aqua regia (related to DIN EN 16174:2012) using the microwave system MARS 5 Xpress and vessels of perfluoroalkoxy alkane (both:
CEM GmbH). For this, $6 \mathrm{ml} \mathrm{35 \%} \mathrm{HCl}$ (supra quality, Carl Roth) and $2 \mathrm{ml} \mathrm{65 \%} \mathrm{HNO}_{3}$ (Merck, subboiled) were added to up to $200 \mathrm{mg}$ of the individual samples. A pre-reaction of $20 \mathrm{~min}$ took place in open vessels. Afterwards, the vessels were closed; the mixtures were heated to $175^{\circ} \mathrm{C}$ within $15 \mathrm{~min}$ and kept at $175^{\circ} \mathrm{C}$ for $10 \mathrm{~min}$. After cooling down, the digestion mixtures were filled up to $25 \mathrm{ml}$ with ultrapure water in volumetric flasks (polymethylpentene, PMP, Vitlab) and transferred to 50-ml centrifuge tubes (PP, Greiner BioOne). After centrifugation (3000 rpm, $15 \mathrm{~min}$ ), the clear supernatants were transferred to $30-\mathrm{ml}$ sample bottles (high-density PE, Thermo Scientific) and stored until further processing.

In addition, total digestions of selected samples were performed for the purpose of quality control, using a pressure digestion system (DAS, Pico Trace) with vessels of polytetrafluoroethylene. For this, $2.5 \mathrm{ml} 65 \%$ $\mathrm{HNO}_{3}$ (Merck, subboiled) was added to $50 \mathrm{mg}$ of the sample, heated up to $45^{\circ} \mathrm{C}$ within $1 \mathrm{~h}$, and kept at $45^{\circ} \mathrm{C}$ for $1 \mathrm{~h}$. After cooling down, $2.5 \mathrm{ml} 40 \% \mathrm{HF}$ and $3 \mathrm{ml}$ $70 \% \mathrm{HClO}_{4}$ (both: Suprapur, Merck) were added; the mixture was heated up to $180{ }^{\circ} \mathrm{C}$ within $8 \mathrm{~h}$ and kept at that temperature for $12 \mathrm{~h}$. The cooled mixture was heated up to $180{ }^{\circ} \mathrm{C}$ again within 4 $5 \mathrm{~h}$ in the evaporation mode and kept there for $14 \mathrm{~h}$ to evaporate the acids. The remaining solids were dissolved in $2 \mathrm{ml} \mathrm{HNO}_{3}$ (Merck, subboiled), $0.6 \mathrm{ml} \mathrm{HCl}$ (Suprapur, Carl Roth), and $7 \mathrm{ml}$ ultrapure water within $8 \mathrm{~h}$ at $150{ }^{\circ} \mathrm{C}$ and filled up to $25 \mathrm{ml}$ with ultrapure water in volumetric flasks (PMP, Vitlab).

Mass fractions of Al, Ca, Fe, K, Mg, Mn, Na, P, S, Si, $\mathrm{Sr}$ and $\mathrm{Ti}$ were analyzed by ICP-OES (inductively coupled plasma-optical emission spectroscopy, 725ES, Agilent Technologies) and mass fractions of Ag, As, B, $\mathrm{Ba}, \mathrm{Cd}, \mathrm{Co}, \mathrm{Cr}, \mathrm{Cs}, \mathrm{Cu}, \mathrm{La}, \mathrm{Li}, \mathrm{Mo}, \mathrm{Nb}, \mathrm{Ni}, \mathrm{Pb}, \mathrm{Rb}, \mathrm{Sb}$, $\mathrm{Sn}, \mathrm{V}, \mathrm{W}, \mathrm{Y}, \mathrm{Zn}$ and $\mathrm{Zr}$ were analyzed by ICP-MS (inductively coupled plasma-mass spectrometry, XSeries II, Thermo Scientific).

Mass fractions of organic and total carbon as well as nitrogen were determined in selected samples using a Vario EL cube element analyzer (Elementar Analysensystem $\mathrm{GmbH}$ ).

\subsection{Quality Control}

For quality control, standard reference materials SRM 1648a Urban Particulate Matter, SRM 1575 Trace 
Elements in Pine Needles (both: National Institute of Standards and Technology) and IPE 952 Grass mixture (Wageningen Evaluating Programs for Analytical Laboratories) were digested with aqua regia and analyzed according to the description above.

Almost all recovery rates for elements in biological reference materials (SRM 1575, IPE 952) are greater than $90 \%$ (lowest rate: $76 \pm 9 \%$ ). For SRM 1648a (urban particulate matter), recovery rates are greater than $90 \%$ for about one-third of the elements but substantially lower (below 70\%) only for $\mathrm{Al}, \mathrm{Cr}, \mathrm{K}, \mathrm{Na}, \mathrm{Rb}$, and $\mathrm{Ti}$. The latter might be due to the fact that urban particulate matter often contains some geogenic particles of which silicates like feldspar (containing $\mathrm{Al}, \mathrm{K}, \mathrm{Na}$, and $\mathrm{Rb}$ ) as well as chromite $\left(\mathrm{FeCr}_{2} \mathrm{O}_{4}\right)$ are not dissolved in aqua regia (Salminen et al. 2005).

Recovery rates were also calculated relating the mass fractions after aqua regia digestion to those after total digestion for both sample materials. They are greater than $90 \%$ for $\mathrm{Ca}, \mathrm{Co}, \mathrm{Cu}, \mathrm{Fe}, \mathrm{K}, \mathrm{Mg}, \mathrm{Mn}, \mathrm{Mo}, \mathrm{P}, \mathrm{Sb}, \mathrm{Sn}$ and $\mathrm{Sr}$ and substantially lower (below 70\%) for $\mathrm{Cr}, \mathrm{Cs}$, $\mathrm{Na}, \mathrm{Nb}, \mathrm{Ni}, \mathrm{Rb}$, Ti and $\mathrm{Zr}$. However, as the tendencies are similar for both sample materials and for SRM 1648a, element mass fractions cannot be regarded as total mass fractions, but element patterns can be compared with each other. (Detailed numbers can be found in Online Resource 1.)

\subsection{Microscopy}

Microscopic pictures of selected sample materials were taken with the digital microscope KEYENCE VHX6000 (KEYENCE GmbH) with a magnification of $\times$ $100-\times 1000$. Material from three exemplary sampling locations (one per type of nearby traffic) as well as nonexposed moss and freshly built webs were regarded to get an optical, qualitative impression on particle retention. Non-milled moss from moss bags was placed directly on the object plate while spider webs were collected on glass slides at the monitoring sites, embedded in a thermoplastic mounting medium (Cargille Meltmount*1.582, Cargille-Sacher Laboratories Inc.) and covered with a cover glass.

\subsection{Data Handling and Statistical Evaluation}

Data pre-treatment, calculations, and univariate statistics were done using MS Excel 2010 (Microsoft Corporation). Mass fractions below the limit of detection (LOD) were replaced by a random value between zero and the LOD and element measurement series with more than $10 \%$ of values below the LOD were excluded from further examination (namely $\mathrm{Ag}$ and $\mathrm{As}$ ). The data was checked for outliers according to Dixon (1951, P $=99 \%$ ) and statistical parameters as well as the test for normal distribution according to David et al. (1954, $P=$ 99\%) were calculated for the data without outliers. Significant differences between spider webs and moss bags were tested for each element using the Wilcoxon signed-rank test (Bortz et al. 2008, pp. 259-261, $P=$ 99\%). Additionally, the Spearman rank correlation between elements in spider webs and moss bags was calculated for each element. Cluster analyses of the autoscaled data including outliers were done with the software R using Ward's algorithm with squared Euclidean distances. Graphical visualizations were edited with CorelDRAW Graphics Suite 2017 (Corel Corporation).

\section{Results and Discussion}

\subsection{Microscopy}

Microscopic images of the two different sample materials were kept to get an optical overview of particle retention of the materials (Fig. 2). Particles can be seen on the surface of moss material after exposure to ambient air (Fig. 2c-g) but not before (panel a). Black particles are attached to the surface of moss exposed at a car traffic location (panel c) and to a smaller extent to moss exposed at a pedestrian area (panel g). In contrast, on moss exposed at a tram and train transport location (panel e) many big, white, sub-rounded particles can be found. Those are likely quartz and/or feldspar sand and silt particles added on the tracks to increase the adhesion of the wheels (Arias-Cuevas and Li 2011).

Fresh spider webs (panel b) have characteristic sticky droplets to which particles adhere after exposure (panels $\mathrm{d}, \mathrm{f}, \mathrm{h}$; for comparison, see Vollrath and Tillinghast 1991). The highest amount of PM can be found on webs from a car traffic location (panel d). This is mainly black, flocculent material similar to brake wear (see Online Resource 2), while some oval, translucent particles were identified as windblown plant material. At the tram and train transport location (panel $\mathrm{f}$ ), fewer and smaller particles can be found. Compared with the moss sample there are less translucent mineral particles but 


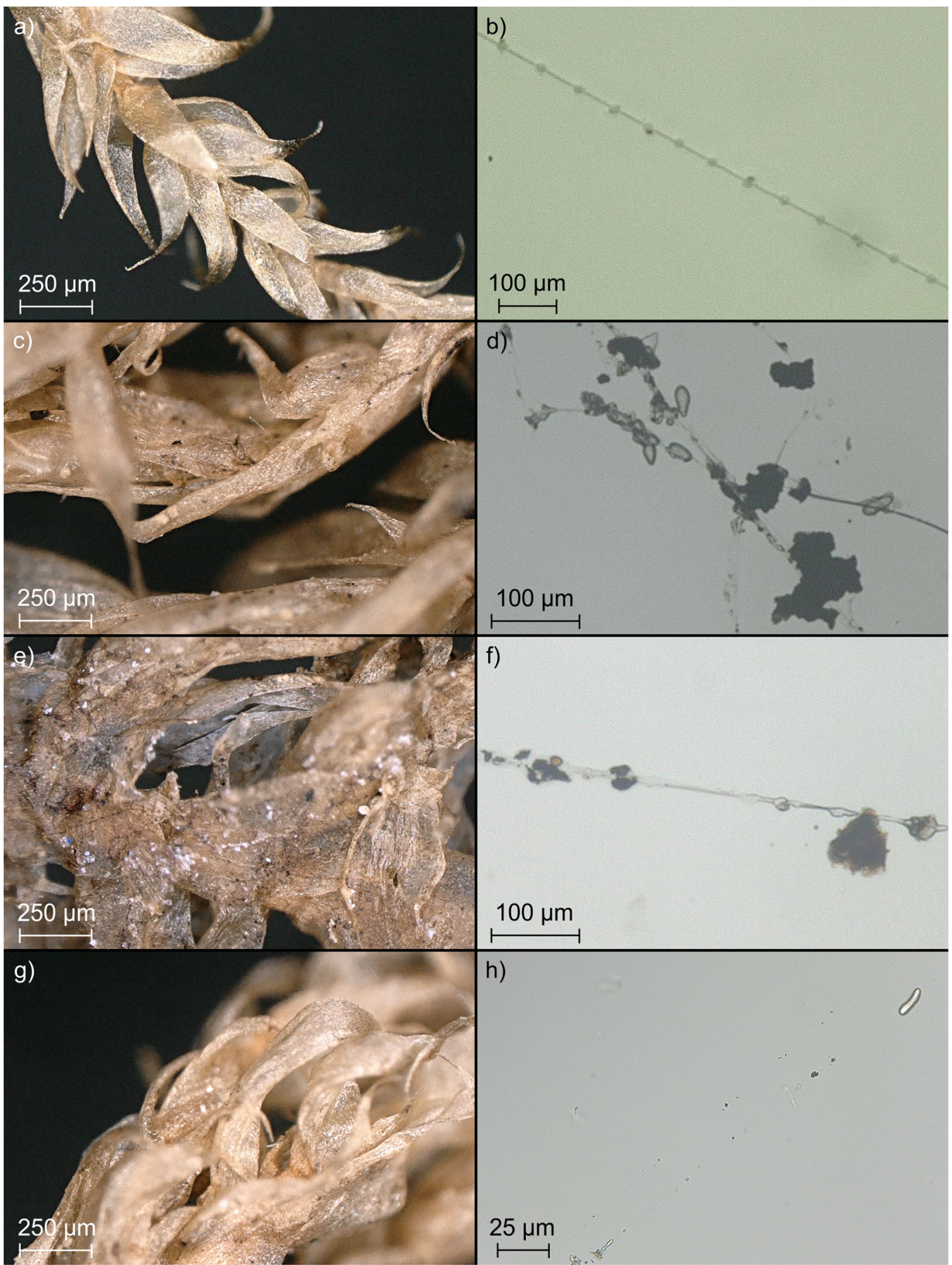

Fig. 2 Microscopic images of sample material (left: moss, right: spider webs) from locations with different types of traffic. a moss prior to exposure, $\mathbf{b}$ fresh spider web early in the morning, $\mathbf{c}, \mathbf{d}$
CA-PAR (car traffic), e, f TR-ARE (tram and train transport), $\mathbf{g}, \mathbf{h}$ PD-IGW (pedestrian area)

particles found on mosses are too heavy to attach to spider webs while particles of biologic origin might not some bigger, brownish particles that are considered as plant material. Possibly the big and heavy minerogenic 
be distinguished optically from the moss material. Those differences are expected to influence the element patterns discussed in the following. Only very few particles adhere to the spider web taken at a pedestrian area (panel h).

Overall, the microscopic images show that the ratio of deposited PM to biological material is much larger for spider webs than for moss bag samples. Besides, particles can be seen and zoomed in better on spider webs as the structure is less complex and can be fixed on a glass slide. This easy optical inspection of spider web samples strengthens the superior suitability of spider webs to sample PM as stated by Rybak and Olejniczak (2014).

\subsection{Moss Bags Vs. Spider Webs: Chemical Composition}

In accordance with the microscopic images, mass fractions of elements in spider webs are generally higher than in moss bag samples with factors ranging from 2 to 15 for most of the elements (e.g. B: $21.3 \mu \mathrm{g} / \mathrm{g}$ in spider webs and $8.96 \mu \mathrm{g} / \mathrm{g}$ in moss bags or Sn: $13.1 \mu \mathrm{g} / \mathrm{g}$ in spider webs and $0.895 \mu \mathrm{g} / \mathrm{g}$ in moss bags). For $\mathrm{Na}$ and $\mathrm{P}$, the factors are 29 and 36, respectively. Detailed numbers can be found in Table 1 (and Online Resource 3 ). While a majority of mass fractions is in the range of trace components $(1000 \mu \mathrm{g} / \mathrm{g} \geq$ median $\geq 1 \mu \mathrm{g} / \mathrm{g}$ ), a higher number of minor components $(10 \% \geq$ median $\geq 1000 \mu \mathrm{g} / \mathrm{g}$ ) can be found for spider webs and the number of ultra-trace components (median $\leq 1 \mu \mathrm{g} / \mathrm{g}$ ) is higher for moss bag samples. The difference between mass fractions of elements in the two sample materials is significant (Wilcoxon signed-rank test, $P=99 \%$ ) for all elements except $\mathrm{Cd}$ and $\mathrm{Pb}$. This does also become visible in Fig. 3. It displays mass fractions of elements in the samples normalized to mass fractions in the upper continental crust, the latter of which are expected to reflect the abundance of elements in geogenic (natural) dust particles. Only for $\mathrm{Cd}$ and $\mathrm{Mn}$ the mass fractions are higher in moss bag samples.

Element patterns for moss bag and spider web samples in Fig. 3 are expected to reflect the general urban air pollution in the study area. Their shapes look similar for most of the elements with comparably high normalized mass fractions, hinting to an enrichment of these elements, for B, Cd, Cu, Mo, Ni, P, Pb, S, Sb, Sn and Zn. While $\mathrm{P}$ and $\mathrm{S}$ occur in the biological materials, the listed metals and metaloids are known to be mainly of anthropogenic origin. They might be derived from sources of PM such as vehicular emissions (e.g. Cd, $\mathrm{Cu}, \mathrm{Pb}$ ), lubricant or fossil fuel combustion in general $(\mathrm{Cd}, \mathrm{Ni}, \mathrm{Pb}, \mathrm{Zn})$, coal combustion $(\mathrm{Pb})$, brake and tire wear for $\mathrm{Cd}, \mathrm{Cu}, \mathrm{Pb}, \mathrm{Sb}, \mathrm{Sn}$ and $\mathrm{Zn}$ and abraded steel particles for B, Mo and Ni (Enamorado-Báez et al. 2015; Johansson et al. 2009; Rampazzo et al. 2008; Salminen et al. 2005; Suvarapu and Baek 2017; Viana et al. 2008; Zhu et al. 2015). It has to be kept in mind that low values for $\mathrm{Al}, \mathrm{Nb}, \mathrm{Si}$, Ti and $\mathrm{Zr}$ in Fig. 3 are due to their incomplete digestion with aqua regia.

Across all orders of magnitude, mass fractions for moss bag samples are in the range of mass fractions for moss bag samples using Hypnum cupressiforme in urban areas in the literature. Adamo et al. (2011) for example found $0.26 \mu \mathrm{g} / \mathrm{g}$ of $\mathrm{Cd}, 5.4 \mu \mathrm{g} / \mathrm{g}$ of $\mathrm{Cr}$, and $1140 \mu \mathrm{g} / \mathrm{g}$ of $\mathrm{Mg}$ in a study in Naples, Italy, while Tretiach et al. (2011) found $0.42 \mu \mathrm{g} / \mathrm{g}, 5.05 \mu \mathrm{g} / \mathrm{g}$, and $1020 \mu \mathrm{g} / \mathrm{g}$ respectively in a study from Trieste, Italy. Median mass fractions in moss bags in this study were $0.291 \mu \mathrm{g} / \mathrm{g} \mathrm{Cd}, 2.28 \mu \mathrm{g} / \mathrm{g} \mathrm{Cr}$, and $1160 \mu \mathrm{g} / \mathrm{g} \mathrm{Mg}$. Results of moss bag biomonitoring (using Hypnum cupressiforme) might therefore be compared across different cities. However, they do likely not stress local pollution features but rather reflect a general urban air pollution. More pronounced differences between cities with different sizes, urban architectures, and climate zones would be expected if mostly local pollution features were reflected. Besides, the mass fractions are higher than those in naturally occurring Hypnum cupressiforme from Ljubljana municipality, stressing the enrichment of metals and metalloids during exposure to ambient air (Berisha et al. 2017). For spider webs, more differences between mass fractions in the literature and mass fractions determined in this study have been found. Often, only well-known heavy metals like $\mathrm{Cd}, \mathrm{Cu}, \mathrm{Pb}$ and $\mathrm{Zn}$, which are expected to be derived mainly from anthropogenic sources, were regarded in spider webs (e.g. Rybak et al. 2012; Rybak et al. 2015). Xiao-Li et al. (2006) for example found mass fractions one to two orders of magnitude higher for $\mathrm{Cd}(0.85-3.37 \mu \mathrm{g} / \mathrm{g})$ and $\mathrm{Pb}(35.4-290 \mu \mathrm{g} / \mathrm{g})$ in webs from Wuhan (China) than we found in this work with median mass fractions of $0.260 \mu \mathrm{g} / \mathrm{g}$ for $\mathrm{Cd}$ and $11.1 \mu \mathrm{g} / \mathrm{g}$ for $\mathrm{Pb}$. Higher levels of PM and its metal mass fractions meet the expectations for the megacity of Wuhan in comparison with the medium-sized city of Jena. Besides, older webs (age up to 60 days) were used in the cited study which might also be a reason for higher mass fractions compared with those in 1-day- 


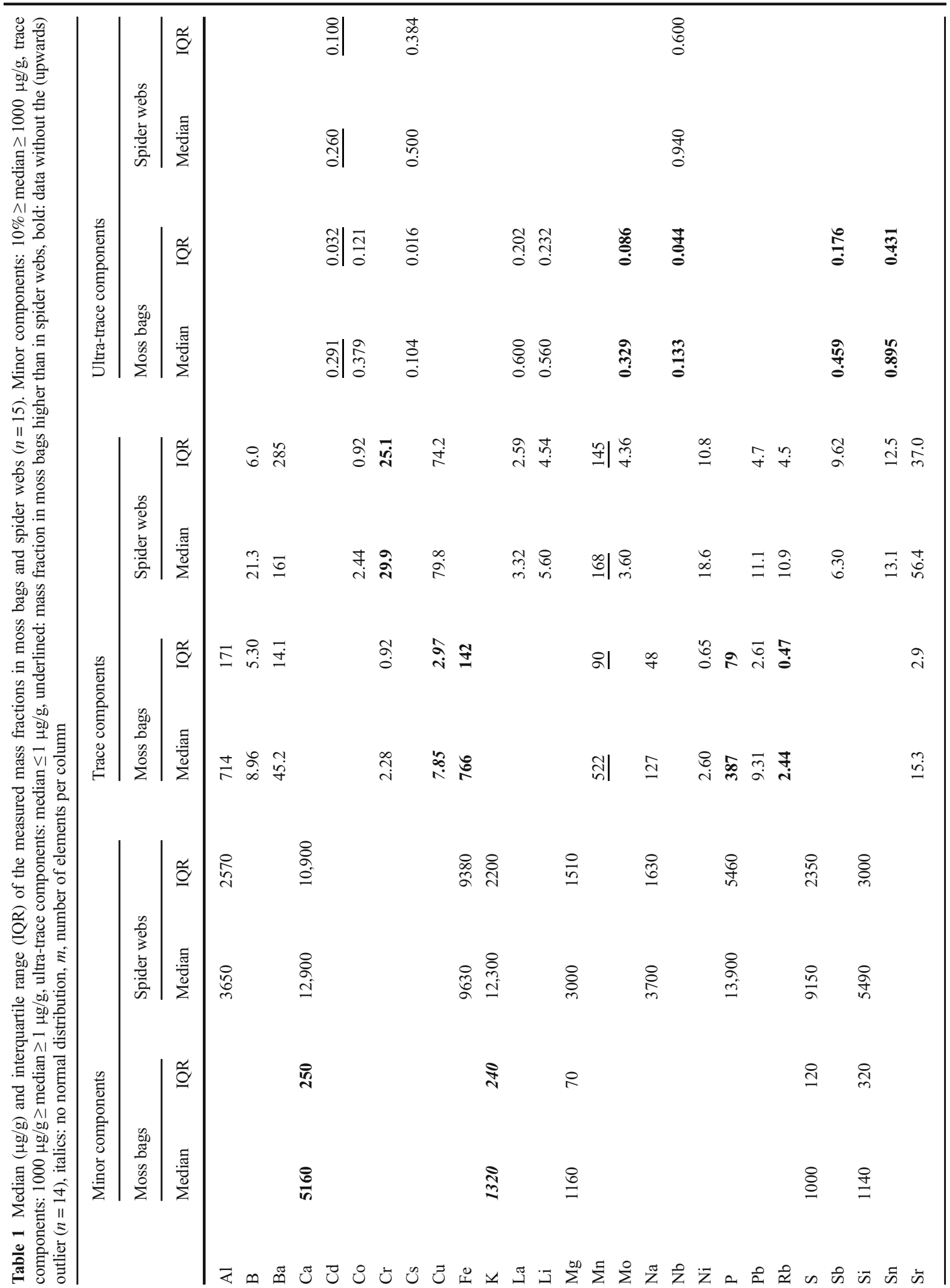




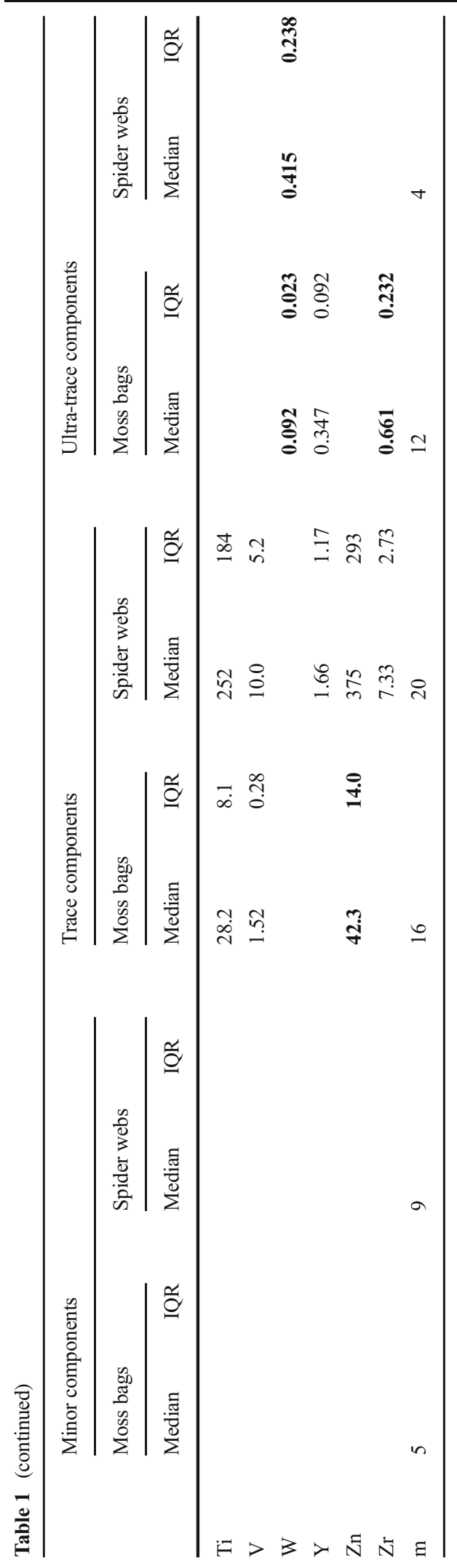

old webs in the present study. Some differences might also be due to the various digestion methods used as they can show different recovery rates. Silicate particles for example can only be digested totally by HF that was used by Adamo et al. (2011) while most of the other studies cited used digestion with $\mathrm{HNO}_{3}$ and $\mathrm{H}_{2} \mathrm{O}_{2}$ (Berisha et al. 2017; Rybak 2015; Xiao-li et al. 2006).

To better compare mass fractions for the two materials and correct them for the diluting effect of the biological carrier material, the mean amount of the biomass in the two materials has been calculated. Mass fractions of the biomass were projected using mean mass fractions of organic carbon in the samples and a sum formula describing the biomass. For moss bags, the sum formula $\mathrm{C}_{12} \mathrm{H}_{20} \mathrm{O}_{10}$ (cellulose) has been used and for spider webs, we applied $\mathrm{C}_{3.38} \mathrm{H}_{5.01} \mathrm{~N}_{1.06} \mathrm{O}_{1.32}$, a sum formula approximated from the fractions of amino acid residues named by Work and Young (1987). Mass fractions measured in the samples were subsequently corrected for the biomass as given in Eq. (1) where $w_{i \text {,cor }}$ is the corrected mass fraction of the element $i, w_{i}$ is the measured mass fraction of the element $i$ (both in $\mu \mathrm{g} / \mathrm{g}$ ), and $w_{\text {bio }}$ is the mass fraction of the biomass (in $\mathrm{g} / \mathrm{g}$ ).

$w_{i, \mathrm{cor}}=w_{i} \cdot \frac{1}{1-w_{\text {bio }}}$

Figure 4 shows boxplots for the sum of all mass fractions measured and for sums of mass fractions corrected for the biomass. For the latter, the difference between the sample types decreases noticeably from a factor of 6.2 to 1.2. Still, the difference is significant for about half of the elements $(\mathrm{B}, \mathrm{Ca}, \mathrm{Cd}, \mathrm{Cr}, \mathrm{Cu}, \mathrm{Fe}, \mathrm{K}$, $\mathrm{Mg}, \mathrm{Mn}, \mathrm{Na}, \mathrm{P}, \mathrm{Pb}, \mathrm{S}, \mathrm{Sb}, \mathrm{Sn}, \mathrm{Sr}, \mathrm{Zn}, \mathrm{Zr}$ ). This leads to two different conclusions: Either the diluting influence of the biomass cannot be corrected for completely by this approach or the influence can be corrected for completely and the remaining differences are due to systematic contrasts of the retention of PM by the two biological materials. The latter might also be deduced from element patterns in Fig. 3. Differences between the element patterns of moss bags and spider webs can be found for $\mathrm{Cd}, \mathrm{Mn}$ and $\mathrm{Pb}$ with comparably high values for moss bag samples. While Mn occurs in the moss material itself as a micronutrient, the differences for $\mathrm{Cd}$ and $\mathrm{Pb}$ cannot be explained by the carrier material itself and likely hint to different particle retention mechanisms of spider webs and moss bags. 


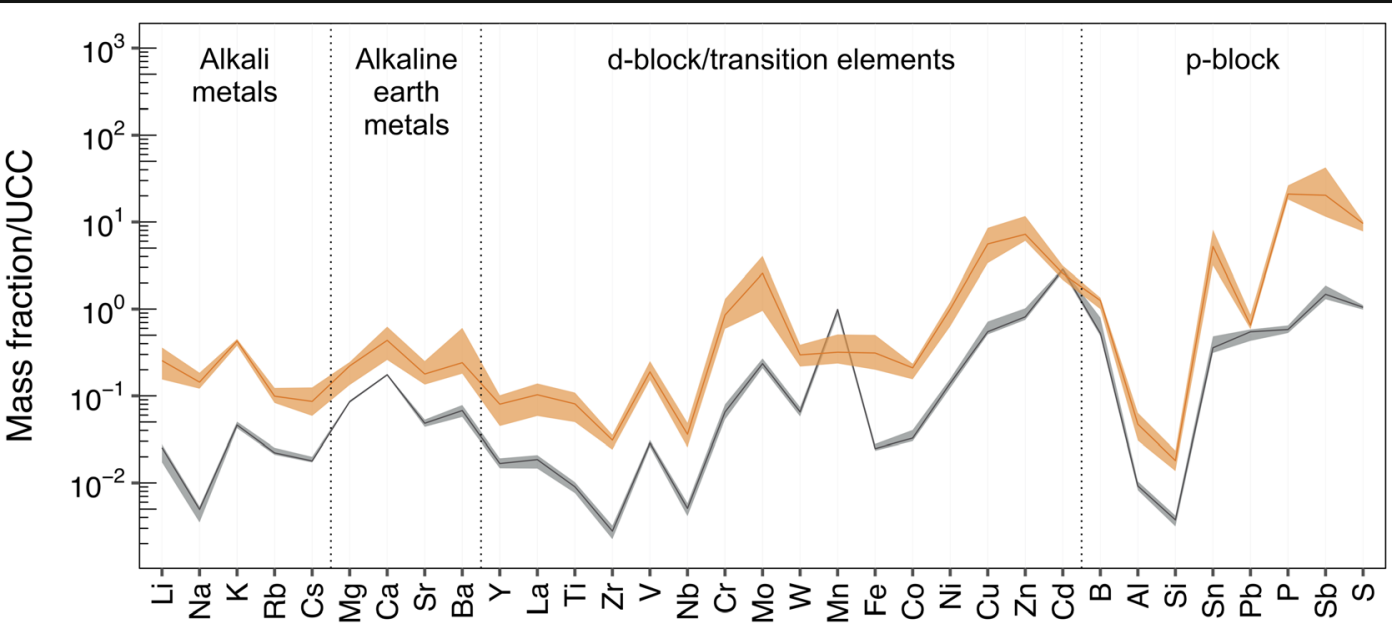

Spider webs: median (line) \pm interquartile range

Fig. 3 Mass fractions of elements determined in moss bag and spider web samples normalized to mass fractions in the upper continental crust (UCC) given by Wedepohl (1995). The

Independent from the significant difference, the corrected mass fractions are in the same range. For some comparison that might be helpful, e.g. to qualitatively differentiate between polluted and unpolluted areas or when using data gained with both methods complementary.

\subsection{Correlation Coefficients as a Tool to Identify Sources of PM}

For an explicit source identification, single samples and the variation of the data can be exploited. The spider web data shows a higher variation (higher interquartile ranges compared with the median) than the moss bag data (Table 1 and Fig. 3). Spider webs thus might reflect small variations in trace element compositions of PM better than moss bags. The higher variation of the spider web data is most likely due to the smaller leveling and diluting influence of the biological material (as it can be inferred from the microscopic images). However, the biological carrier material itself might be more heterogeneous for spider webs, introducing some of the variations, as they are woven by individual orb-weaving spiders (mainly Araneus diadematus).

Spearman rank correlation coefficients $\left(r_{\mathrm{s}}\right.$, calculated using the mass fractions measured) are a statistical tool that examines the variation of a dataset and is often used to describe the relationship between two variables. In this work, groups of elements with significant correlation are used to describe different sources of PM. Only
Moss bags: median (line) \pm interquartile range

normalization has been performed to allow for an easy optical comparison of elements with different natural abundances

for some elements, significant correlations $\left(\left|r_{\mathrm{s}}\right| \geq 0.65\right.$, $P=99 \%$ ) are found for both spider webs and moss bags and a higher number is found for the spider web than for the moss bag dataset (Table 2, numbers in Online Resource 3). Thus, a stronger relationship between the elements in spider webs is deduced. For a better understanding, joint coefficients can be regarded as forming sub-matrices with predominantly significant coefficients that are ascribed to the different sources of $\mathrm{PM}$ or influences of the sample material. In this sense, the sub-matrix of $\mathrm{K}, \mathrm{P}$ and $\mathrm{S}$ likely describes the dilution of PM by the biological material while correlations of K, $\mathrm{P}$ and $\mathrm{S}$ with other elements are negative and the elements are included in both spider webs and mosses (Rachold et al. 1992; Strasburger et al. 2014; Work and Young 1987). Al, Co, La, Nb, Ti, V, Y and Zr form another sub-matrix that is ascribed to PM of geogenic origin, such as natural and anthropogenically influenced soil erosion. $\mathrm{La}, \mathrm{Nb}, \mathrm{Y}$ and $\mathrm{Zr}$ are common elements found in high mass fractions in the Quaternary loess deposits of Central Germany which are also present in the surroundings of Jena (Salminen et al. 2005; Seidel 1993). Cu, Sb, Sn and $\mathrm{Zn}$ correlating with each other have been ascribed to brake wear in the literature (Berisha et al. 2017; Furusjö et al. 2007; Johansson et al. 2009). Their sub-matrix likely describes brake wear as a part of the influence of automobile traffic to PM. A differentiation of geogenic/natural and anthropogenic sources of PM is thus possible with both methods. 

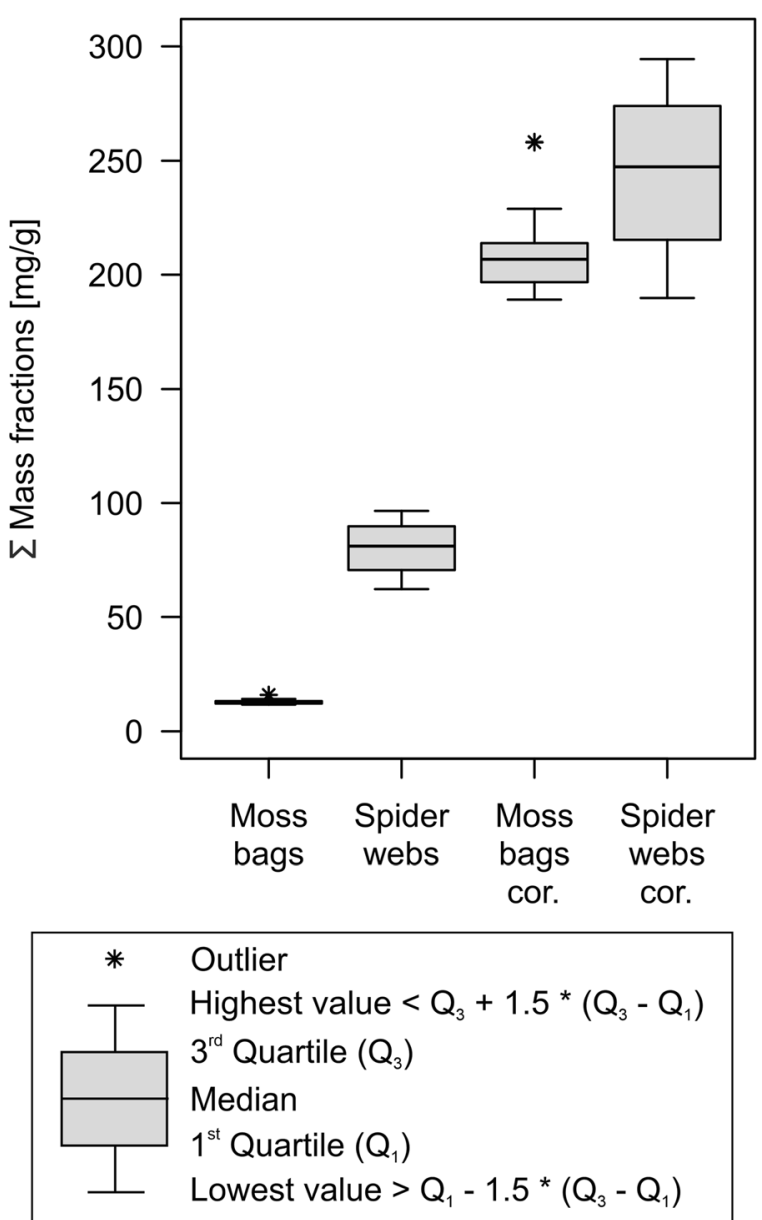

Fig. 4 Boxplot of the sum of all element mass fractions measured in moss bag and spider web samples and of mass fractions corrected for the amount of biomass (cor)

An additional sub-matrix of $\mathrm{Cr}, \mathrm{Fe}, \mathrm{Mo}$ and $\mathrm{Ni}$ can be found for the spider web data but not for the moss bags. Those elements are ascribed to the abrasion of rail and/ or tram tracks consisting of steel alloys containing all four elements (Johansson et al. 2009; Lahd Geagea et al. 2007). Furthermore, the sub-matrix describing (resuspended) geogenic PM contains more elements for the spider web dataset than for the moss bags. Additional elements are typical for either calcareous rocks $(\mathrm{Ca}, \mathrm{Mg}, \mathrm{Sr})$ or marine evaporates $(\mathrm{B}, \mathrm{Cs}, \mathrm{Li})$ that can also be found in the surroundings of Jena (Salminen et al. 2005; Seidel 2003).

In contrast, solely for the moss bag dataset elements correlating not only with a few other ones but also with a high number of elements can be found. Those elements are likely derived from different sources. Especially Co, $\mathrm{Cr}, \mathrm{Fe}, \mathrm{Ni}$ and $\mathrm{Zn}$ have been described as being mainly of anthropogenic origin and derived from various sources (Dongarrà et al. 2007; Rybak 2015; Suvarapu and Baek 2017).

The fact that there are only very few significant correlation coefficients between the sample materials (Table 3) further stresses the differences between the two monitoring methods. If the sample materials would accumulate PM in identical ways, significant correlation coefficients for the same element in moss bag and spider web samples should be expected. A correlation like that can only be found for $\mathrm{Cu}, \mathrm{Mo}, \mathrm{Sb}, \mathrm{Sn}$ and $\mathrm{Zn}$ that have been already ascribed to brake wear or car traffic in a broader sense. Most striking is also the correlation of $\mathrm{Ba}$ in moss bags with $\mathrm{Al}, \mathrm{Ca}, \mathrm{Cd}, \mathrm{Cs}, \mathrm{La}, \mathrm{Li}, \mathrm{Mg}, \mathrm{Pb}, \mathrm{Sr}, \mathrm{Y}$ and $\mathrm{Zr}$ in spider webs. Most of the latter elements have already been discussed as being of geogenic/natural origin. $\mathrm{Cd}$ and $\mathrm{Pb}$ are almost completely of anthropogenic origin but can often only be ascribed to a more diffuse pollution rather than a single source (Enamorado-Báez et al. 2015; Suvarapu and Baek 2017). Ba, correlating with all of these elements, can be derived from both natural and anthropogenic sources like sedimentary rocks, unleaded fuel, lubricant oils, and brake fillings (Sternbeck et al. 2002). This correlation between the sample materials might therefore be due to diffusely distributed PM from different sources, which is entrapped in the moss bags.

Overall, differences in correlation coefficients match the hypothesis that the influence of local sources (in this case types of traffic) is more pronounced in the spider web dataset while a more diffuse anthropogenic influence can be seen in the moss bag dataset.

\subsection{Cluster Analyses}

To further identify sources of PM and effectively distinguish or group sampling locations, multivariate methods can be applied. In some studies, this has already been done but only for single datasets (e.g. Barandovski et al. 2015; Rybak 2015; Ştefănuț et al. 2019). Here, cluster analyses have been performed with the mass fractions measured in moss bags and spider webs, and the resulting dendrograms are contrasted with each other (Fig. 5). At a relative distance of $15 \%$, four stable clusters can be found for the moss bag samples. While the location with the highest traffic volume (CAPAR) is clearly cut off, the other clusters cannot be ascribed to a specific source or circumstance. They contain locations with different types of nearby traffic, 
Table 2 Joint correlation matrices (Spearman rank correlation $r_{\mathrm{s}}$ ) for moss bags and spider webs. Only significant correlations $\left(\left|r_{\mathrm{s}}\right| \geq\right.$ $0.65, P=99 \%)$ are regarded. The color code shows if the correlation is significant only for the moss bag dataset (61 significant correlations), the spider webs dataset (114 significant correlations) or both (85 significant correlations); - indicates a negative correlation. Different sub-matrices are formed for moss bags and spider web samples

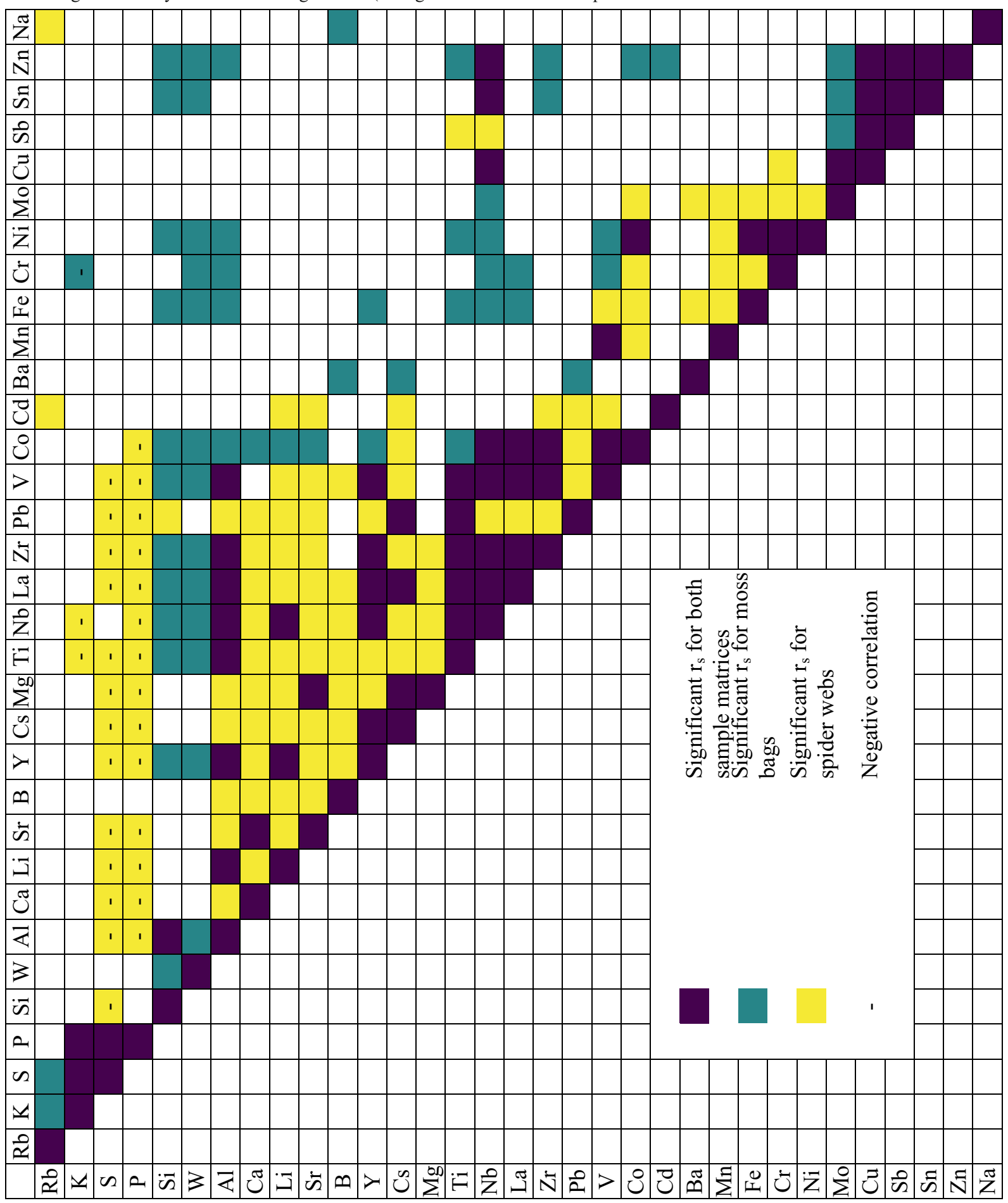


Table 3 Spearman rank correlation coefficients between moss bag and spider web data. Only significant correlations $\left(\left|r_{\mathrm{s}}\right| \geq 0.65, P=99 \%\right)$ are shown. A distinct correlation between the same elements in the two matrices can only be calculated for $\mathrm{Cu}, \mathrm{Mo}, \mathrm{Sb}, \mathrm{Sn}$ and $\mathrm{Zn}$

\begin{tabular}{|c|c|c|c|c|c|c|c|c|c|c|c|c|c|c|c|c|c|c|c|}
\hline $\begin{array}{l}\text { Spider webs } \\
\text { Moss bags }\end{array}$ & $\mathrm{Al}$ & $\mathrm{Ca}$ & $\mathrm{Li}$ & $\mathrm{Sr}$ & $\mathrm{Y}$ & $\mathrm{Cs}$ & $\mathrm{Mg}$ & $\mathrm{Nb}$ & $\mathrm{La}$ & $\mathrm{Zr}$ & $\mathrm{Pb}$ & $\mathrm{Cd}$ & $\mathrm{Cr}$ & $\mathrm{Ni}$ & Mo & $\mathrm{Cu}$ & $\mathrm{Sb}$ & $\mathrm{Sn}$ & $\mathrm{Zn}$ \\
\hline $\mathrm{Nb}$ & & & & & & & & & & & & & 0.65 & & 0.75 & & & & \\
\hline $\mathrm{Zr}$ & & & & & & & & & & & & & & & & & 0.67 & & \\
\hline $\mathrm{Ba}$ & 0.68 & 0.77 & 0.75 & 0.79 & 0.69 & 0.78 & 0.66 & & 0.68 & 0.69 & 0.65 & 0.71 & & & & & & & \\
\hline $\mathrm{Ni}$ & & & & & & & & & & & & & & 0.67 & & & & & \\
\hline Mo & & & & & & & & & & & & & & & 0.67 & 0.80 & 0.77 & 0.82 & 0.75 \\
\hline $\mathrm{Cu}$ & & & & & & & & & & & & & & & & 0.86 & 0.84 & 0.85 & 0.85 \\
\hline $\mathrm{Sb}$ & & & & & & & & & & & & & & & & 0.65 & 0.73 & 0.66 & 0.76 \\
\hline $\mathrm{Sn}$ & & & & & & & & & & & & & & & & 0.83 & 0.89 & 0.84 & 0.85 \\
\hline $\mathrm{Zn}$ & & & & & & & & & & & & & & & & 0.75 & 0.71 & 0.78 & 0.71 \\
\hline $\mathrm{Na}$ & & & & & & & & 0.65 & & & & & & & & & & & \\
\hline
\end{tabular}

different elevations, and different locations in the town. In contrast, at $15 \%$ relative distance, the spider web samples are clearly distinguished according to the nearby type of traffic, coinciding with the results of Rybak and Olejniczak (2014), who suggested spider webs as a useful indicator of traffic emissions but with respect to polycyclic aromatic hydrocarbons. This direct comparison witnesses that spider webs reflect small-scale differences in anthropogenic PM better than moss bags.

\subsection{Possible Differences Due to the Methodology}

Overall, the differences between moss bag and spider web biomonitoring might not only be due to differences

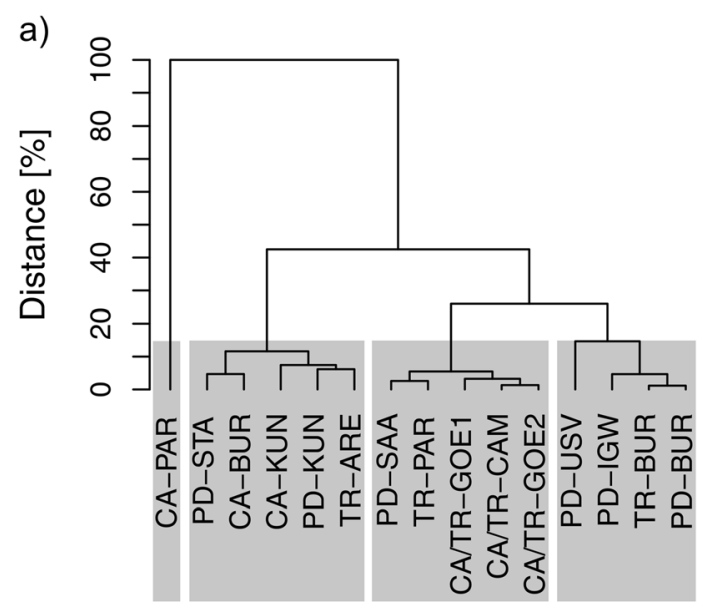

Fig. 5 Dendrograms (Ward's algorithm, squared Euclidean distances) depicting the cluster analyses of moss bags (a) and spider webs (b). At $15 \%$ relative distance the sampling locations are separated according to the nearby sort of traffic (CA, car; PD, in texture and relation of sample material to PM as described above but also to different requirements/ characteristics of the sampling approaches. These characteristics must also be taken into consideration when selecting one method over the other. While orb webs are renewed nearly every day, mosses need several weeks to accumulate a significant amount of PM (Aničić Urošević and Milićević 2020; Ares et al. 2012; Nentwig 1980). Thus, the latter give integrated values reflecting a longer period while spider webs allow for a better temporal resolution. Still, moss bags and spider webs in this study are expected to reflect the same PM that did not change substantially over the exposure period of the moss bags. The repeated sampling and analysis of webs

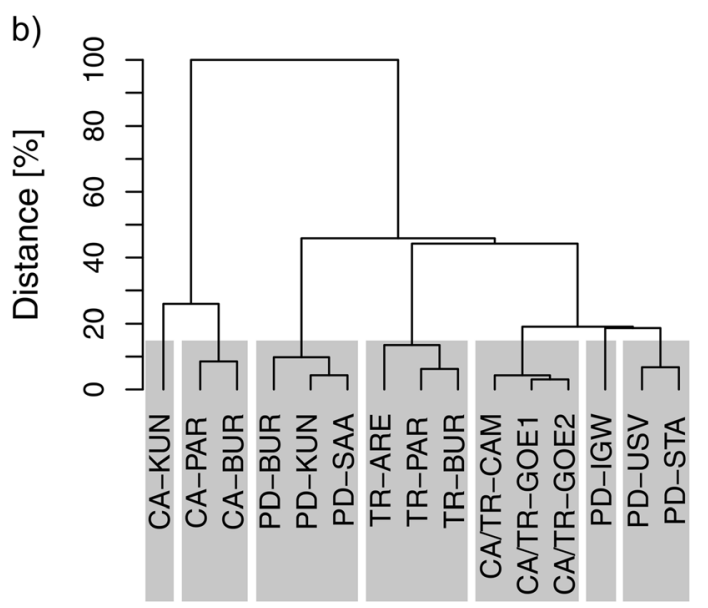

pedestrian; TR, tram/train; CA/TR, car and tram/train) within the spider web dataset. A similar pattern cannot be seen within the moss bag dataset 
from two locations (TR-ARE and CA-BUR) every 2 weeks during the moss bag's exposure period showed comparably low standard deviations for element mass fractions. The selection of one or the other biomonitoring method therefore also depends on the desired temporal resolution.

Furthermore, the sampling height is different for the two methods: Mosses were sampled $2.5 \mathrm{~m}$ above ground level, and the spider webs at $0.5-1.2 \mathrm{~m}$. The height of the spider web sampling has been predefined by the height of the structures (handrails) from which they have been sampled. Moss bags had to be exposed in greater height to prevent losses due to vandalism. Near ground level emissions like those from traffic are probably more pronounced next to the surface while the influence of mixing, leading to less local variation, increases with height. Even though Capozzi et al. (2016) described a main influence by traffic for moss bags at a height of $4 \mathrm{~m}$, an influence of mixing already in a height of $2.5 \mathrm{~m}$ cannot be ruled out completely by means of the results presented. Air circulation will also transport mainly smaller particles into a height of $2.5 \mathrm{~m}$ compared with a height between 0.5 and $1.2 \mathrm{~m}$. This could also be seen in the microscopic images (Fig. 2). Bigger particles have a stronger influence on the mass fractions of elements which likely leads to a better discrimination of sources or sampling locations. From a health perspective, a lower height might be of greater interest, as this is the height of inhalation for children, which suffer disproportionally much from PM exposure (Fang et al. 2005; Landrigan et al. 2018). Still, it might not be possible to expose moss bags next to ground level as they will likely be damaged or stolen by people. As spider web samples consist of a high number of individual webs that do not attract as much attention as moss bags, a considerable effect of vandalism is not expected for the spider webs.

\section{Conclusion}

In this work, two different biomonitoring methods for (trace) elements in particulate matter (PM) have been compared, focusing on their potential use for monitoring and source identification. Element mass fractions are significantly higher in spider webs than in moss bag samples. A calculation to account for the diluting effect of the biological material leads to fewer but still existing significant differences, hinting to different adsorptions of dust particles. This can also be seen partially in microscopic images of the samples. Element patterns, correlation coefficients, and cluster analyses show some differences for the two sample materials. For spider webs, they can clearly be ascribed to different sources of PM, leading to a clustering of the sampling locations in accordance with the type of nearby traffic. This source identification is less pronounced for the moss bag dataset with an undefined clustering of the sampling locations. However, a single moss bag sampling campaign reflects PM from a longer period of time (several weeks) than one sampling campaign of orb webs (one to a few days). As a result, it is recommended to use moss bags for long-term screening on a rather regional scale. For a local, short-term source identification spider web (orb web) data should be used to exploit the higher variance in the data, the smaller influence of the biological material, and the stronger relationships between the elements as found in this study. Further studies might focus on possibly different capture mechanisms for PM of the biological materials, which has not been a major part of this study.

Acknowledgments We would like to thank the central laboratory for water analytics \& chemometrics at Helmholtz Centre for Environmental Research (Magdeburg) for performing element analyses of carbon and nitrogen and the group of Microbial Communication at Friedrich Schiller University Jena for providing the equipment for cryo-milling. Access to the digital microscope was kindly provided by the group of General and Historical Geology at Friedrich Schiller University Jena. Additionally, we would like to thank the Kommunalservice Jena for permitting the use of street lamps for the installation of moss bags and Dietrich Berger, Friedrich Schiller University Jena, for the identification of the moss species. The anonymous reviewers are kindly acknowledged for their constructive comments and suggestions.

Authors' Contributions All authors contributed to the study conception and design. Material preparation, data collection, and analysis were performed by Neele van Laaten, Michael Pirrung, Dirk Merten, and Wolf von Tümpling. The first draft of the manuscript was written by Neele van Laaten and all authors commented on previous versions of the manuscript. All authors read and approved the final manuscript.

Funding Open Access funding enabled and organized by Projekt DEAL. The first author received a scholarship from the International Max Planck Research School for Global Biogeochemical Cycles.Data AvailabilityNot applicable.

\section{Compliance with Ethical Standards}

Conflict of Interest The authors declare that they have no conflict of interest. 
Code Availability Not applicable.

Open Access This article is licensed under a Creative Commons Attribution 4.0 International License, which permits use, sharing, adaptation, distribution and reproduction in any medium or format, as long as you give appropriate credit to the original author(s) and the source, provide a link to the Creative Commons licence, and indicate if changes were made. The images or other third party material in this article are included in the article's Creative Commons licence, unless indicated otherwise in a credit line to the material. If material is not included in the article's Creative Commons licence and your intended use is not permitted by statutory regulation or exceeds the permitted use, you will need to obtain permission directly from the copyright holder. To view a copy of this licence, visit http://creativecommons.org/licenses/by/4.0/.

\section{References}

Adamo, P., Bargagli, R., Giordano, S., Modenesi, P., Monaci, F., Pittao, E., et al. (2008). Natural and pre-treatments induced variability in the chemical composition and morphology of lichens and mosses selected for active monitoring of airborne elements. Environmental Pollution, 152(1), 11-19.

Adamo, P., Giordano, S., Sforza, A., \& Bargagli, R. (2011). Implementation of airborne trace element monitoring with devitalised transplants of Hypnum cupressiforme Hedw.: assessment of temporal trends and element contribution by vehicular traffic in Naples city. Environmental Pollution, 159(6), 1620-1628.

Aničić Urošević, M., \& Milićević, T. (2020). Moss bag biomonitoring of airborne pollutants as an ecosustainable tool for air protection management: urban and agricultural scenario. In V. Shukla \& N. Kumar (Eds.), Environmental concerns and sustainable development volume 1: air, water and energy resources (pp. 29-59). Gateway East: Springer Nature.

Ares, A., Aboal, J. R., Carballeira, A., Giordano, S., Adamo, P., \& Fernández, J. A. (2012). Moss bag biomonitoring: a methodological review. Science of the Total Environment, 432, 143158.

Ares, A., Fernández, J. A., Carballeira, A., \& Aboal, J. R. (2014). Towards the methodological optimization of the moss bag technique in terms of contaminants concentrations and replicability values. Atmospheric Environment, 94, 496-507.

Arias-Cuevas, O., \& Li, Z. (2011). Field investigations into the adhesion recovery in leaf-contaminated wheel-rail contacts with locomotive sanders. Proceedings of the Institution of Mechanical Engineers, Part F: Journal of Rail and Rapid Transit, 225(5), 443-456.

Ayedun, H., Adewole, A., Osinfade, B. G., Ogunlusi, R. O., Umar, B. F., \& Rabiu, S. A. (2013). The use of spider webs for environmental determination of suspended trace metals in industrial and residential areas. Journal of Environmental Chemistry and Ecotoxicology, 5(2), 21-25.

Babczyńska, A., Wilczek, G., \& Migula, P. (2006). Effects of dimethoate on spiders from metal pollution gradient. Science of the Total Environment, 370(2-3), 352-359.
Barandovski, L., Frontasyeva, M. V., Stafilov, T., Šajn, R., \& Ostrovnaya, T. M. (2015). Multi-element atmospheric deposition in Macedonia studied by the moss biomonitoring technique. Environmental Science and Pollution Research, 22(20), 16077-16097.

Berisha, S., Skudnik, M., Vilhar, U., Sabovljević, M., Zavadlav, S., \& Jeran, Z. (2017). Trace elements and nitrogen content in naturally growing moss Hypnum cupressiforme in urban and peri-urban forests of the Municipality of Ljubljana (Slovenia). Environmental Science and Pollution Research, 24(5), 4517-4527.

Bortz, J., Lienert, G. A., \& Boehnke, K. (2008). Verteilungsfreie Methoden in der Biostatistik. Berlin, Heidelberg: Springer.

Capozzi, F., Giordano, S., Aboal, J. R., Adamo, P., Bargagli, R., Boquete, T., et al. (2016). Best options for the exposure of traditional and innovative moss bags: a systematic evaluation in three European countries. Environmental Pollution, 214, 362-373.

Capozzi, F., Sorrentino, M. C., Di Palma, A., Mele, F., Arena, C., Adamo, P., et al. (2020). Implication of vitality, seasonality and specific leaf area on PAH uptake in moss and lichen transplanted in bags. Ecological Indicators, 108, 105727.

David, H. A., Hartley, H. O., \& Pearson, E. S. (1954). The distribution of the ratio, in a single normal sample, of range to standard deviation. Biometrika, 41(3-4), 482-493.

Di Palma, A., Capozzi, F., Spagnuolo, V., Giordano, S., \& Adamo, P. (2017). Atmospheric particulate matter intercepted by moss-bags: relations to moss trace element uptake and land use. Chemosphere, 176, 361-368.

Dixon, W. J. (1951). Ratios involving extreme values. Annals of Mathematical Statistics, 22(1), 68-78.

Dongarrà, G., Manno, E., Varrica, D., \& Vultaggio, M. (2007). Mass levels, crustal component and trace elements in PM10 in Palermo, Italy. Atmospheric Environment, 41(36), 79777986.

Enamorado-Báez, S. M., Gómez-Guzmán, J. M., Chamizo, E., \& Abril, J. M. (2015). Levels of 25 trace elements in highvolume air filter samples from Seville (2001-2002): sources, enrichment factors and temporal variations. Atmospheric Research, 155, 118-129.

European Union. (2004). Directive 2004/107/EC of the European Parliament and of the Council of 15 December 2004 relating to arsenic, cadmium, mercury, nickel and polycyclic aromatic hydrocarbons in ambient air. Official Journal of the European Union, L, 23, 3-16.

European Union. (2008). Directive 2008/50/EC of the European Parliament and the Council of 21 May 2008 on ambient air quality and cleaner air for Europe. Official Journal of the European Union, L, 152, 1-43.

Fang, G.-C., Wu, Y.-S., Huang, S.-H., \& Rau, J.-Y. (2005). Review of atmospheric metallic elements in Asia during 2000-2004. Atmospheric Environment, 39(17), 3003-3013.

Furusjö, E., Sternbeck, J., \& Cousins, A. P. (2007). PM10 source characterization at urban and highway roadside locations. Science of the Total Environment, 387(1-3), 206-219.

Gieré, R., \& Querol, X. (2010). Solid particulate matter in the atmosphere. Elements, 6(4), 215-222.

Górka, M., Bartz, W., \& Rybak, J. (2018). The mineralogical interpretation of particulate matter deposited on Agelenidae and Pholcidae spider webs in the city of Wrocław (SW 
Poland): a preliminary case study. Journal of Aerosol Science, 123, 63-75.

Johansson, C., Norman, M., \& Burman, L. (2009). Road traffic emission factors for heavy metals. Atmospheric Environment, 43(31), 4681-4688.

Kardel, F., Wuyts, K., Maher, B. A., Hansard, R., \& Samson, R. (2011). Leaf saturation isothermal remanent magnetization (SIRM) as a proxy for particulate matter monitoring: Interspecies differences and in-season variation. Atmospheric Environment, 45(29), 5164-5171.

Lahd Geagea, M., Stille, P., Millet, M., \& Perrone, T. (2007). REE characteristics and $\mathrm{Pb}, \mathrm{Sr}$ and $\mathrm{Nd}$ isotopic compositions of steel plant emissions. Science of the Total Environment, 373(1), 404-419.

Landrigan, P. J., Fuller, R., Acosta, N. J. R., Adeyi, O., Arnold, R., Basu, N., et al. (2018). The Lancet Commission on pollution and health. Lancet, 391(10119), 462-512.

Lelieveld, J., Evans, J. S., Fnais, M., Giannadaki, D., \& Pozzer, A. (2015). The contribution of outdoor air pollution sources to premature mortality on a global scale. Nature, 525(7569), 367-371.

Nentwig, W. (1980). Wie funktionieren Spinnennetze? Biologie in unserer Zeit, 10(4), 117-119.

Norouzi, S., Khademi, H., Faz Cano, A., \& Acosta, J. A. (2015). Using plane tree leaves for biomonitoring of dust borne heavy metals: a case study from Isfahan, Central Iran. Ecological Indicators, 57, 64-73.

Rachold, V., Heinrichs, H., \& Brumsack, H.-J. (1992). Spinnenweben: Natürliche Fänger atmosphärisch transportierter Feinstäube. Naturwissenschaften, 79, 175178.

Rampazzo, G., Masiol, M., Visin, F., Rampado, E., \& Pavoni, B. (2008). Geochemical characterization of PM10 emitted by glass factories in Murano, Venice (Italy). Chemosphere, 71(11), 2068-2075.

Rutkowski, R., Rybak, J., Rogula-Kozłowska, W., Bełcik, M., Piekarska, K., \& Jureczko, I. (2019). Mutagenicity of indoor air pollutants adsorbed on spider webs. Ecotoxicology and Environmental Safety, 171, 549-557.

Rybak, J. (2015). Accumulation of major and trace elements in spider webs. Water, Air, \& Soil Pollution, 226(4), 105-116.

Rybak, J., \& Olejniczak, T. (2014). Accumulation of polycyclic aromatic hydrocarbons (PAHs) on the spider webs in the vicinity of road traffic emissions. Environmental Science and Pollution Research, 21(3), 2313-2324.

Rybak, J., Sówka, I., \& Zwoździak, A. (2012). Preliminary assessment of use of spider webs for the indication of air contaminants. Environment Protection Engineering, 38(3), 175-181.

Rybak, J., Spówka, I., Zwoździak, A., Fortuna, M., \& TrzeplaNabagło, K. (2015). Evaluation of the usefulness of spider webs as an air quality monitoring tool for heavy metals. Ecological Chemistry and Engineering S, 22(3), 389-400.

Rybak, J., Rogula-Kozłowska, W., Jureczko, I., \& Rutkowski, R. (2019). Monitoring of indoor polycyclic aromatic hydrocarbons using spider webs. Chemosphere, 218, 758-766.

Salminen, R., Batista, M. J., Bidovec, M., Demetriades, A., de Vivo, B., de Vos, W., et al. (2005). Geochemical atlas of Europe. Part 1 - background information, methodology and maps. Espoo: Geological Survey of Finland.
Salmond, J. A., \& McKendry, I. G. (2009). Influences of meteorology on air pollution concentrations and processes in urban areas. In R. M. Harrison \& R. E. Hester (Eds.), Air quality in urban environments (pp. 23-41). Cambridge: Royal Society of Chemistry.

Seidel, G. (1993). Geologie von Jena. Weimar: Thüringischer Geologischer Verein.

Seidel, G. (2003). Geologie von Thüringen. Stuttgart: Schweizerbart.

Shvetsova, M. S., Kamanina, I. Z., Frontasyeva, M. V., Madadzada, A. I., Zinicovscaia, I. I., Pavlov, S. S., et al. (2019). Active moss biomonitoring using the "moss bag technique" in the park of Moscow. Physics of Particles and Nuclei Letters, 16(6), 994-1003.

Ştefănuţ, S., Öllerer, K., Manole, A., Ion, M. C., Constantin, M., Banciu, C., et al. (2019). National environmental quality assessment and monitoring of atmospheric heavy metal pollution - a moss bag approach. Journal of Environmental Management, 248, 109224.

Sternbeck, J., Sjödin, Å., \& Andréasson, K. (2002). Metal emissions from road traffic and the influence of resuspension results from two tunnel studies. Atmospheric Environment, 36(30), 4735-4744.

Strasburger, E., Noll, F. C., Schimper, A. F. W., Kadereit, J. W., Körner, C., Kost, B., et al. (2014). Lehrbuch der Pflanzenwissenschaften. Berlin: Springer Spektrum.

Suvarapu, L. N., \& Baek, S.-O. (2017). Determination of heavy metals in the ambient atmosphere. Toxicology and Industrial Health, 33(1), 79-96.

Tretiach, M., Pittao, E., Crisafulli, P., \& Adamo, P. (2011). Influence of exposure sites on trace element enrichment in moss-bags and characterization of particles deposited on the biomonitor surface. Science of the Total Environment, 409(4), 822-830.

Urbat, M., Lehndorff, E., \& Schwark, L. (2004). Biomonitoring of air quality in the Cologne conurbation using pine needles as a passive sampler - part I: Magnetic properties. Atmospheric Environment, 38(23), 3781-3792.

USGS (2004). Shuttle radar topography mission, 3 arc second scene, unfilled unfinished 2.0. Global Land Cover Facility, University of Maryland, College Park, Maryland, February 2000.

Viana, M., Kuhlbusch, T. A. J., Querol, X., Alastuey, A., Harrison, R. M., Hopke, P. K., et al. (2008). Source apportionment of particulate matter in Europe: a review of methods and results. Journal of Aerosol Science, 39(10), 827-849.

Vollrath, F., \& Tillinghast, E. K. (1991). Glycoprotein glue beneath a spider web's aqueous coat. Naturwissenschaften, 78(12), 557-559.

Vuković, G., Aničić Urošević, M., Škrivanj, S., Milićević, T., Dimitrijević, D., Tomašević, M., et al. (2016). Moss bag biomonitoring of airborne toxic element decrease on a small scale: a street study in Belgrade, Serbia. Science of the Total Environment, 542, 394-403.

Wedepohl, K. H. (1995). The composition of the continetal crust. Geochimica et Cosmochimica Acta, 59, 1217-1232.

Wessel, P., Smith, W. H. F., Scharroo, R., Luis, J., \& Wobbe, F. (2013). Generic mapping tools: improved version released. Eos, Transactions, American Geophysical Union, 94(45), 409-410. 
WHO (2013). Review of evidence on health aspects of air pollution - REVIHAAP Project. http://www.euro.who.int/ data/assets/pdf_file/0004/193108/REVIHAAP-Finaltechnical-report-final-version.pdf?ua=1. Accessed 04 March 2020.

Work, R. W., \& Young, C. T. (1987). The amino acid compositions of major and minor Ampullate silks of certain orb-webbuilding spiders (Araneae, Araneidae). Journal of Arachnology, 15(1), 65-80.

Xiao-li, S., Yu, P., Hose, G. C., Jian, C., \& Feng-xiang, L. (2006). Spider webs as indicators of heavy metal pollution in air.
Bulletin of Environmental Contamination and Toxicology, 76(2), 271-277.

Zhu, X., Kuang, Y., Li, J., Schroll, R., \& Wen, D. (2015). Metals and possible sources of lead in aerosols at the Dinghushan nature reserve, southern China. Rapid Communications in Mass Spectrometry, 29(15), 1403-1410.

Publisher's Note Springer Nature remains neutral with regard to jurisdictional claims in published maps and institutional affiliations. 